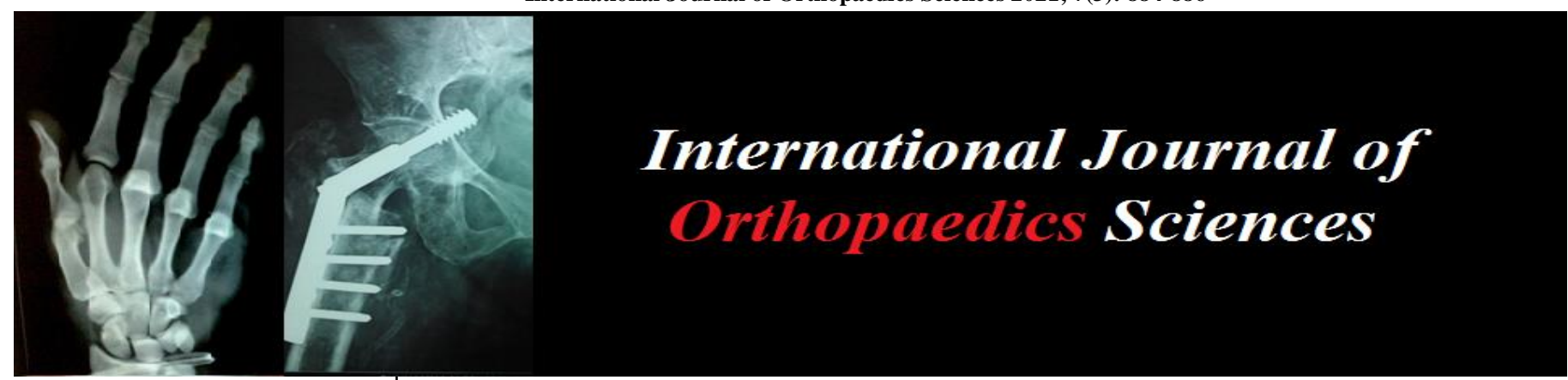

E-ISSN: 2395-1958

P-ISSN: 2706-6630

IJOS 2021; 7(3): 884-886

(C) 2021 IJOS

www.orthopaper.com

Received: 10-05-2021

Accepted: 16-06-2021

Dr. Naveen Rathor

Assistant Professor, Department

of Orthopaedics, American

International Institute of

Medical Science, Udaipur,

Rajasthan, India

Dr. Suresh Kumar Bhatnagar

Assistant Professor, Department

of Orthopaedics, American

International Institute of

Medical Science, Udaipur,

Rajasthan, India

Dr. Momin Aadil Sumer

Senior Resident, Department of

Orthopaedics, American

International Institute of

Medical Science, Udaipur,

Rajasthan, India

Corresponding Author: Dr. Naveen Rathor

Assistant Professor, Department

of Orthopaedics, American

International Institute of

Medical Science, Udaipur,

Rajasthan, India

\section{Intrawound vancomycin powder as the prophylaxis of surgical site infection after invasive lumber spine surgery: A prospective study}

\author{
Dr. Naveen Rathor, Dr. Suresh Kumar Bhatnagar and Dr. Momin Aadil \\ Sumer
}

DOI: https://doi.org/10.22271/ortho.2021.v7.i3m.2850

\section{Abstract}

Objectives: To evaluate the efficacy of locally administered vancomycin (VCM) powder for prophylaxis of SSI after invasive lumber spine surgery.

Material and Method: This prospective study was conducted upon 85 patients at American international institute of medical science, Udaipur (Rajasthan). All patient were operated for invasive spine surgery from May 2019 to April 2020 and follow up was done for minimum one year of duration. In patients of the VCM group ( $\mathrm{n}=42), 1$ gm VCM powder was locally administered in the surgical wound and Patients who did not receive VCM treatment were set as a control group $(n=43)$. We compared the patient's background, Operation time, Intraoperative blood loss, usage of implants, presence of deep SSI, and side effects between the two groups.

Results: There were no significant differences between the groups in age, gender, and BMI. The operation time and the intraoperative blood loss were longer and greater in the VCM group than in the control group. Implants were used in $85 \%$ of the VCM group, and in $31 \%$ of the control group ( $P<$ $0.001)$. Deep SSI was observed in one patient $(2.38 \%)$ of the VCM group, whereas it was observed in 3 patients $(6.97 \%)$ in the control group. No systemic side effects of vancomycine were observed in any of the cases.

Conclusion: Administration of intrawound VCM powder might be effective to prevent SSI in cases with high risks of infection.

Keywords: Surgical site infection, vancomycin hydrochloride, intrawound administration, invasive spine surgery

\section{Introduction}

Surgical site infections (SSIs) are one of the most serious complication of spine surgery. The incidence rate of deep SSI after spine surgery is reported to be $1-14 \%$, with most of the causative bacteria being vancomycin (VCM) susceptible. Additional surgery for debridement or the removal of instrumented materials might be necessary when antibiotic therapy for SSI is not effective. However, both surgical debridement and failed antibiotic treatment result in long-term hospitalization and increased morbidity of patient. It has been reported that local application of VCM powder to wounds is effective after spine surgery. There is little evidence of local VCM application in the prophylaxis of SSI in cases with a high risk of infection. In this study, we investigated the efficacy of locally applied VCM powder in the prevention of SSIs after spine surgery.

\section{Materials and Methods}

\section{Study Design}

This study was carried out after obtaining the approval from institutional ethical committee and informed consent of each participant. This prospective study was conducted upon 85 patients at American international institute of medical science, Udaipur (Rajasthan). All patient were operated for invasive spine surgery from May 2019 to April 2020 and follow up for a minimum one year of duration. 
In patients of the VCM group $(n=42)$, VCM powder was administered in the wound before closing wound. Patients who did not receive VCM treatment were set as a control group ( $n=43)$. patients who had surgery for existing infections and other comorbidities were excluded from the study.

\section{Method}

All patients received identical standard operative and postoperative care procedures based on protocol of department. Patients with diabetes underwent perioperative glycemic control, which was performed by physician. Surgical sites were prepared with $10 \%$ iodine for three times and covered with iodine-containing dressing preoperatively. Cefazolin sodium ( $1 \mathrm{~g})$ was administered as an intravenous infusion within $60 \mathrm{~min}$ before the start of surgery, and then every three hours during surgery. No patient was administered intravenous VCM prior to or during surgery. Normothermia was maintained in all patients. In patients who received VCM treatment (VCM group), $1 \mathrm{gm}$ VCM hydrochloride powder was applied to the wound and bone grafts before the wound was closed. Patients who did not receive VCM treatment were used as a control group. We examined the following items and compared them between the two groups: patient's background, surgery duration, intraoperative blood loss, use or non-use of implants, number of fused vertebrae, presence or absence of deep SSI based on World Health Organization criteria and the occurrence of adverse effects (allergies, renal failure, red man syndrome, or auditory disorders) associated with VCM use.
For statistical analysis, we performed a Chi-square test, a Fisher's exact test, and a $t$-test. $\mathrm{P}$ values less than 0.05 were considered statistically significant. The data have been presented as mean \pm standard deviation.

\section{Results}

There were 42 patients in the VCM group and 43 patients in the control group. All patients were followed more than one year. Follow up period (mean \pm standard deviation) was 18.4 \pm 5.2 months in the VCM group and $17.5 \pm 5.8$ months in the control group $(p=0.43)$. The primary surgeon did not differ between the groups $(\mathrm{p}=0.72)$. The demographic and surgery data of the patients are shown in Table $1 \&$ Table 2. There were no significant differences between the groups in mean age, gender ratio, and body mass index ( $p=0.62, p=0.88$, and $p=0.48$, respectively). The VCM group showed significantly higher values in the mean surgery duration and intraoperative blood loss than the control group $(p<0.005$ and $p<0.001$, respectively). Implants were used in $85.70 \%$ and $32.5 \%$ of the patients in the VCM and control groups, respectively $(p<0.001)$.

Table 1: Demographic data of the patients

\begin{tabular}{|c|c|c|c|}
\hline & Control group & VCM group & P-value \\
\hline No. of cases & 43 & 42 & \\
\hline Male ratio (\%) & $42 \%$ & $48 \%$ & 0.81 \\
\hline Age (yr) & $50.3 \pm 22.2$ & $48.4 \pm 23.8$ & 0.60 \\
\hline BMI $(\mathrm{kg} / \mathrm{m} 2)$ & $22.0 \pm 4.7$ & $22.6 \pm 5.9$ & 0.81 \\
\hline DM & $11.62 \%$ & $42.85 \%$ & $<0.001$ \\
\hline
\end{tabular}

Table 2: Surgical data of the patients

\begin{tabular}{|c|c|c|c|}
\hline & Control group & VCM group & p-value \\
\hline Surgery duration (min) & $109 \pm 43$ & $180 \pm 70$ & $<0.005$ \\
\hline Blood loss (ml) & $250 \pm 150$ & $340 \pm 250$ & $<0.001$ \\
\hline Implant usage & $32.55 \%$ & $85.70 \%$ & $<0.001$ \\
\hline No. of fused vertebrae & $3 \pm 2$ & $4 \pm 3$ & $<0.001$ \\
\hline \multicolumn{3}{|c|}{ Details of spinal disorder } \\
\hline 1) Scoliosis & 06 & 08 & \\
\hline 2) degenerative disease & 09 & 11 & \\
\hline 3) P.I.V.D & 22 & 14 & \\
\hline 4) Traumatic & 06 & 09 & \\
\hline
\end{tabular}

The incidence of deep SSI was $2.38 \%$ (one patient) in the VCM group and $6.97 \%$ (3 patients) in the control group (Table 3). All four cases of infection was associated with use of implant. The following causative bacteria were detected in the infection cases: Methicillin-resistant Staphylococcus aureus (1 case), Methicillin-resistant Staphylococcus epidermidis (2 cases), and Escherichia coli (1 case). All of
Staphylococcus strains were VCM susceptible. One of the infected patients received successful conservative treatment with antibiotics; however, in the other three cases, additional debridement surgery had to be performed. No adverse effects (allergies, renal failure, red man syndrome, auditory disorders and local soft tissue problems) usually associated with the use of VCM were observed in any of the cases.

Table 3: Details of patients with deep surgical site infection

\begin{tabular}{|c|c|c|c|c|c|c|}
\hline group & Age(yr)/sex & Bacterial strain & Disease/surgery & Surgery duration & Blood loss & treatment \\
\hline VCM group & 32/M & MRSE & \#L1 -L2 Vertebrae/posterior fixation & $170 \mathrm{~min}$ & $480 \mathrm{ml}$ & debridement \\
\hline control & 52/M & MRSE & Degenerative listhesis /PLIF & $210 \mathrm{~min}$ & $400 \mathrm{ml}$ & debridement \\
\hline control & $57 / \mathrm{M}$ & E.COLI & Degenerative listhesis/PLIF & $260 \mathrm{~min}$ & $450 \mathrm{ml}$ & nonsurgical \\
\hline control & 71/M & MRSA & Degenerative Scoliosis/PLIF & $230 \mathrm{~min}$ & $290 \mathrm{ml}$ & debridement \\
\hline
\end{tabular}

E. coli, escherichia coli; MRSE, methicillin-resistant staphylococcus epidermidis; MRSA, methicillin resistant staphylococcus aureus; PLIF, posterior lumbar interbody fusion.

\section{Discussion}

The results showed that the duration of surgery, blood loss rate, rate of implant use, and the number of fused vertebrae were longer or higher in the VCM group than they were in the control group. We found that the surgeons tended to apply
VCM into the wounds when the surgery was or had a high risk of infection. Although there was a high risk of developing infections in many of the cases, deep SSI was observed only in one patient of the VCM group.

There is little evidence of local VCM application in the 
prophylaxis of SSI in cases with a high risk of infection. Tubaki et al. reported that local application of VCM to surgical wound did not significantly reduce the incidence of infection after spine surgery in a randomized controlled study. In that study, there were limitations such as the lack of power analysis and a low infection rate (1.61-1.68\%), which indicated that the risk of developing an infection was relatively low. Various retrospective studies have reported decreased relative risks for SSI (0.086- 0.23$)$ and safety after intrawound use of VCM.

The biggest concern about intrawound VCM is its safety. Sweet et al. studied the serum level of VCM after intrawound application of $2 \mathrm{~g} \mathrm{VCM}$ in 178 patients who had undergone spine surgery. The minimum sensitivity of the blood test to VCM was $0.6 \mu \mathrm{g} / \mathrm{ml}$ in that study. The results showed that VCM was not detected in serum in $80 \%$ of the patients. In $20 \%$ of the patients in whose serum VCM was detected, the average VCM level was $1.6 \mu \mathrm{g} / \mathrm{ml}$ at postoperative day 1.3) The serum level was quite low compared to the recommended safety margin of VCM $(<15 \mu \mathrm{g} / \mathrm{ml})$. The molecular mass of VCM is high; therefore, it is not easily absorbed into the blood and the risks of its side effects, such as renal failure and red man syndrome, are quite low. Although none of the case measured the serum concentration of VCM, no adverse effects were observed in the current study. Furthermore, it has been reported that an effective concentration of VCM is detected in wound drainage on the third day after surgery. Furthermore, it has been shown that VCM does not suppress in vitro proliferation of human osteoblasts or delay in vivo bone fusion in posterior lumbar fusion in rats. These indicate that intrawound VCM would not obstruct bone healing.

There were several limitations in this study. Firstly, patients' background information and surgical interventions were different between the VCM and control groups.

In addition, The surgeons tended to use VCM in cases where the risk of infection was high. Since we did not set strict criteria for the application of intrawound VCM, VCM use was the surgeon's choice. Because patients in the VCM group had a higher risk of developing infections and underwent more invasive surgeries than those in the control group. Therefore, we might have biased for the effect of VCM in preventing SSIs.

Another limitation was the small number of subjects used in the study. As a result, the statistical power was not high enough to compare the occurrence of SSIs between the two groups. we therefore plan to conduct a randomized controlled trial with an adequate number of cases.

In conclusion, the intrawound application of VCM powder might be safe and effective in preventing SSIs after spine surgeries in cases with a high risk of infection.

\section{References}

1. Radcliff KE, Neusner AD, Millhouse PW, Harrop JD, Kepler CK, Rasouli MR, et al. What is new in the diagnosis and prevention of spine surgical site infections? Spine J 2015;15:336-347.

2. Kobayashi K, Imagama S, Ito Z, Ando K, Yagi H, Hida $\mathrm{T}$, et al. Is a Drain Tip Culture Required After Spinal Surgery? Clin Spine, 2016; Epub ahead of print.

3. Sweet FA, Roh M, Sliva C. Intrawound application of vancomycin for prophylaxis in instrumented thoracolumbar fusions: efficacy, drug levels, and patient outcomes. Spine (Phila Pa 1976) 2011;36:2084-2088.

4. Strom RG, Pacione D, Kalhorn SP, Frempong-Boadu AK. Decreased risk of wound infection after posterior
5. cervical fusion with routine local application of vancomycin powder. Spine (Phila $\mathrm{Pa}$ 1976), 2013;38:991-994.

6. Dennis HH, Wei DT, Darren KZ, Shantakumar JT, Kumar N, Lau LL, et al. Is Intraoperative Local Vancomycin Powder the Answer to Surgical Site Infections in Spine Surgery? Spine (Phila Pa 1976) 2017;42:267-274.

7. Allegranzi B, Zayed B, Bischoff P, Kubilay NZ, de Jonge $\mathrm{S}$, de Vries F, et al. New WHO recommendations on intraoperative and postoperative measures for surgical site infection prevention: an evidence-based global perspective. Lancet Infect Dis, 2016.

8. Tubaki VR, Rajasekaran S, Shetty AP. Effects of using intravenous antibiotic only versus local intrawound vancomycin antibiotic powder application in addition to intravenous antibiotics on postoperative infection in spine surgery in 907 patients. Spine (Phila $\mathrm{Pa}$ 1976) 2013;38:2149-2155.

9. Vitale MG, Riedel MD, Glotzbecker MP, Matsumoto H, Roye DP, Akbarnia BA, et al. Building consensus: development of a Best Practice Guideline (BPG) for surgical site infection (SSI) prevention in high-risk pediatric spine surgery. J Pediatr Orthop 2013;33:471478.

10. Thomson AH, Staatz CE, Tobin CM, Gall M, Lovering AM. Development and evaluation of vancomycin dosage guidelines designed to achieve new target concentrations. J Antimicrob Chemother 2009;63:1050-1057.

11. Philp AM, Raja S, Philp A, Ede MP, Jones SW. The effect of Vancomycin and Gentamicin Antibiotics on Human Osteoblast Proliferation, Metabolic Function and Bone Mineralisation. Spine (Phila Pa 1976), 2016; Epub ahead of print.

12. Mendoza MC, Sonn KA, Kannan AS, Bellary SS, Mitchell SM, Singh G, et al. The effect of vancomycin powder on bone healing in a rat spinal rhBMP-2 model. J Neurosurg Spine 2016;25:147-153. 